\title{
Triênio do Curso de Iniciação à Programação de Computadores para mulheres: uma análise preliminar das turmas e das egressas
}

\author{
Renata Lima Ribeiro de Sena \\ Departamento de Ciência da Computação - Universidade Federal da Bahia (UFBA) \\ Grupo de Pesquisa e Extensão em Informática, Educação e Sociedade - Onda Digital \\ Av. Adhemar de Barros, s/n - Ondina - CEP 40.170-110 - Salvador - BA. \\ renatalrdesena@gmail.com
}

Abstract. This article presents and discusses the results of the analysis of triennium of the Course of Initiation to Programming (CIProg) women-only classes, an initiative by Meninas Digitais - Regional Bahia which seeks to bring women closer to Computer Science through programming. The discussion that follows is a brief history of this initiative and of the CIProg. Also, it presents a historical analysis of the classes, its specifications and particularities, the profile of graduates regarding schooling and the policy of quotas practiced in the selection edicts for the CIProg.

Resumo. Este artigo apresenta e discute resultados da análise do triênio das turmas exclusivas para mulheres do Curso de Iniciação à Programação (CIProg), ação do Meninas Digitais - Regional Bahia que visa aproximar mulheres das áreas de Computação por meio da programação. A discussão que segue passa por um breve histórico dessa iniciativa e do CIProg, além de apresentar uma análise histórica das turmas, suas especificações e particularidades, o perfil de egressas quanto à escolaridade e a política de cotas praticada nos editais de seleção para o CIProg.

\section{Introdução}

Em vistas do processo de democratização do acesso ao ensino, da ascensão de movimentos que visam a equiparação de gênero e de medidas de inclusão em diversas esferas da sociedade, torna-se crescente o número de pesquisas que discutem a igualdade de gênero na área de Tecnologia da Informação e Comunicação (TIC) [Maciel et. al. 2016]. Há, no entanto, uma demanda expressiva por projetos que atuem em paralelo às políticas públicas já concebidas. Nesse contexto surgem projetos como o Meninas Digitais (MD) ${ }^{1}$, no cenário nacional, e Meninas Digitais - Regional Bahia $(\mathrm{MD}-\mathrm{BA})^{2}$, como um pólo regional do primeiro.

O presente artigo tem por objetivo apresentar uma análise preliminar das turmas exclusivas para mulheres do Curso de Iniciação a Programação (CIProg) Nível 1 concluídas no triênio 2016 - 2018, o perfil das egressas quanto à escolaridade e a evolução da política de cotas nos editais de seleção do CIProg, almejando identificar

\footnotetext{
${ }^{1}$ http://meninas.sbc.org.br/

2 http://www.meninasdigitais.ufba.br/
} 
pontos a serem melhorados visando a continuidade e posterior expansão dessa ação de extensão.

\section{Cenário Brasileiro de Tecnologia da Informação e Comunicação: discrepância de gênero e tentativas de equiparação}

De acordo com o relatório Educação Superior em Computação - Estatísticas, em cursos de TIC no Brasil nos últimos cinco anos as mulheres são, aproximadamente, 13,8\% do total de ingressantes e $16 \%$ do total de concluintes [Sociedade Brasileira de Computação 2017]. Na Bahia as estatísticas do cenário nacional repetem-se. Nos cursos de graduação oferecidos pelo Departamento de Ciência da Computação na Universidade Federal da Bahia (UFBA), de acordo com dados de 2016, as mulheres são cerca de 10\% e 17,8\% nos Bacharelados em Ciência da Computação e Sistemas de Informação, respectivamente, e 16,7\% na Licenciatura em Computação [Santos et. al. 2017].

A partir da necessidade de fomento à entrada e permanência de mulheres na área de TIC evidenciada pela discrepância de gênero no Brasil e na Bahia, nascem iniciativas como o MD - de abrangência nacional - e seus pólos regionais, tais como o MD-BA. Concebido em 2011, o programa MD tem por objetivo a divulgação da área de TIC visando despertar o interesse de estudantes do ensino médio ou tecnológico bem como dos últimos anos do ensino fundamental [Maciel et. al. 2016]. Fundado em 2016, o projeto MD-BA possui como singularidade o recorte de raça. Assim, o projeto tem como um dos seus objetivos a inclusão de meninas e mulheres negras, oriundas ou não da rede de ensino público, na área de TIC, visando oportunizar o contato desse público minoritário com a ciência e tecnologia [Lobo et. al. 2018].

Em seu ano de fundação, o MD-BA realizou diversas ações com intuito de possibilitar o contato do público feminino com a área de TIC [Santos et. al. 2017]. Dentre elas destaca-se a inédita promoção de uma turma exclusiva para mulheres no CIProg, um curso de iniciação à programação de computadores oferecido semestralmente, desde 2013, pelo Projeto Onda Solidária de Inclusão Digital, que visa apresentar noções iniciais de programação e desenvolver habilidades para resolução de problemas por meio de algoritmos e do raciocínio computacional [Ferreira et. al. 2016]. O curso é ofertado por meio de edital de seleção e é geralmente oferecido em dois níveis: o CIProg Nível 1 com ementa constituída por conteúdos como variáveis, constantes, operadores aritméticos e lógicos, estruturas de controle, estruturas de repetição, e vetores; e o CIProg Nível 2 com conteúdos como matrizes, strings, funções, tipos abstratos de dados e ponteiros.

Antes da atuação do MD-BA foram oferecidas 4 turmas mistas, as quais tiveram proporção de $23,5 \% ; 32,3 \% ; 37,5 \%$ e $34,3 \%$ de mulheres entre os egressos. A crescente procura de mulheres pelo curso evidenciada por essas porcentagens, a contradição com a alta taxa de desistência destas ao longo dos cursos e o nascimento do MD-BA foram fatores de motivação para a criação de turmas exclusivas para mulheres no CIProg. Destaca-se a relevância de turmas exclusivas por acreditar-se que elas criam um ambiente no qual as mulheres se sentem mais confortáveis, além de desenvolver a autoconfiança [Santos et. al. 2018]. Desde 2016 foram ofertadas 8 turmas exclusivas para mulheres do CIProg Nível 1, obtendo 68 concluintes ao todo, firmando o projeto na 
agenda de ações visando equiparação de gênero. Com o triênio dessa ação, faz-se interessante realizar uma análise com o intuito de identificar particularidades das turmas e das egressas a fim de alterar o que se faça necessário para possibilitar a permanência e ampliação dessa ação.

\section{Metodologia da Pesquisa}

A metodologia desta pesquisa possui abordagem mista e seu percurso foi construído por um processo de seleção, extração e processamento das informações contidas nas fichas de inscrição e nos editais de seleção para o $\operatorname{CIProg}^{3}$ e suas posteriores análise e interpretação. A partir da extração, julgou-se relevante analisar três parâmetros: evolução das turmas, perfil das egressas quanto à escolaridade e a evolução da política de cotas nos editais de seleção. Foram coletados dados sobre a quantidade de instrutoras/monitoras; vagas ofertadas; inscritas, matriculadas e concluintes das turmas; a escolaridade das egressas no momento no curso e a área dos cursos das egressas do Ensino Superior (ES).

\section{Avaliação dos Resultados}

Destacam-se aqui algumas das informações que se fazem relevantes para essa análise preliminar (vide Seção 3). Vale salientar que as Turmas 5 e 6 foram regidas pelo mesmo edital e que a Turma 8 teve início em abril/2019 e será encerrada em junho/2019 o que impossibilita a análise de suas egressas. Apesar disso, foram analisados dados da turma e do edital que a regulamenta.

\subsection{Análise das Turmas e da Escolaridade das Egressas}

Analisando o gênero dos instrutores/monitores das turmas exclusivas para mulheres do CIProg obtemos resultados animadores: a Turma 1 não contava com mulheres; as Turma 2 e 3 contava com 3 e 2 mulheres, respectivamente; e, desde a Turma 4 o quadro é inteiramente feminino contando com 3 mulheres nas Turmas 4 a 6 e 5 nas Turmas 7 e 8. A tendência é que a participação feminina se mantenha ou aumente visto que algumas egressas demonstraram interesse em atuar nas turmas. Este é um fato relevante considerando que a falta de referência desencadeia a falta de identificação com área e influencia negativamente a participação de mulheres em áreas de TIC [Maia 2016].

Sobre as vagas ofertadas (Figura 1-a), deve-se salientar que estão limitadas ao espaço físico disponível na UFBA. Devido ao aumento da demanda para uso dos laboratórios de informática usados nas primeiras turmas, com 40 computadores, e à ausência de um laboratório específico para ações de extensão, desde a Turma 4 optou-se por realizar o curso em espaço próprio do Grupo de Pesquisa e Extensão Onda Digital, com 8 computadores. Permite-se a matrícula acima de 8 alunas desde que utilizem seus computadores pessoais. É possível que a diminuição na oferta de vagas no decorrer do tempo tenha influenciado a diminuição do número de inscritas, visto que as baixas desses parâmetros se dão no mesmo período e em proporções semelhantes (ver Figura 1-a).

Quanto à escolaridade das egressas a discrepância é evidente: enquanto as egressas do ES, em curso e completo, representam $67,6 \%$ do total, apenas $8,8 \%$ era do

\footnotetext{
${ }^{3}$ http://wiki.dcc.ufba.br/OndaDigital/
} 
Ensino Médio (EM), 10,3\% do Ensino Técnico (ET) e 10,3\% havia concluído o EM/ET e não havia ingressado no ES. Sobre as egressas do ES vale destacar que dentro da Área BI (Figura 1-b) 68,7\% pertencia ao Bacharelado Interdisciplinar em Ciência e Tecnologia. As egressas de Área I também representam uma significativa porcentagem (Figura 1-b). A discrepância na escolaridade das egressas e a quantidade de egressas do ES de áreas que possuem alguma relação com TIC evidenciam a necessidade de traçar estratégias visando tanto a inserção de mulheres do EM/ET quanto possibilitar o interesse de mulheres das demais áreas nas turmas exclusivas do CIProg.
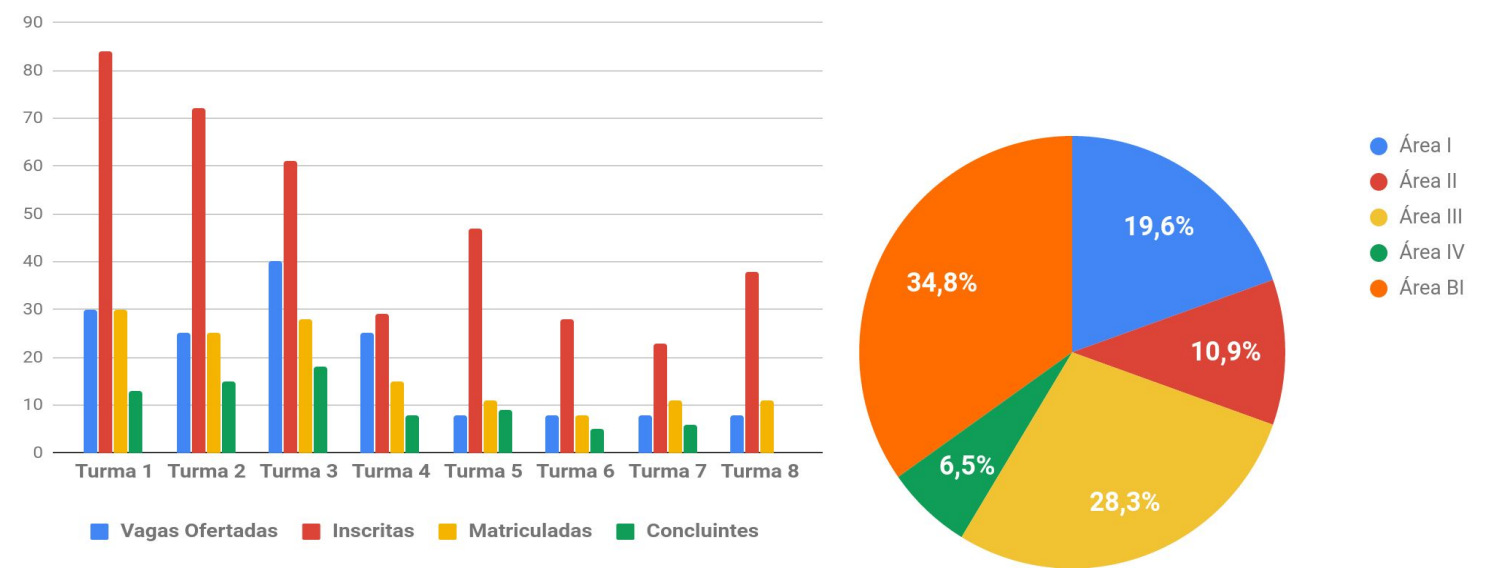

Figura 1. (a) Evolução das turmas na relação vagas, inscrições, matrículas e conclusões. (b) Áreas dos cursos das egressas com ES.

\subsection{Política de Cotas nos Editais de Seleção}

Ansiando cumprir o objetivo do MD-BA de promover o contato de meninas do EM/ET com a área de TIC e observando a baixa participação da comunidade externa, nas turmas exclusivas ou não, os editais de seleção para o CIProg passaram a cotizar as vagas ofertadas a partir da Turma 3 (Figura 2). A necessidade da implementação de uma política de cotas é evidenciada pelos dados da Turma 1, por exemplo, cujas egressas do EM e ET representavam, respectivamente, $15,3 \%$ e 7,7\% do total.

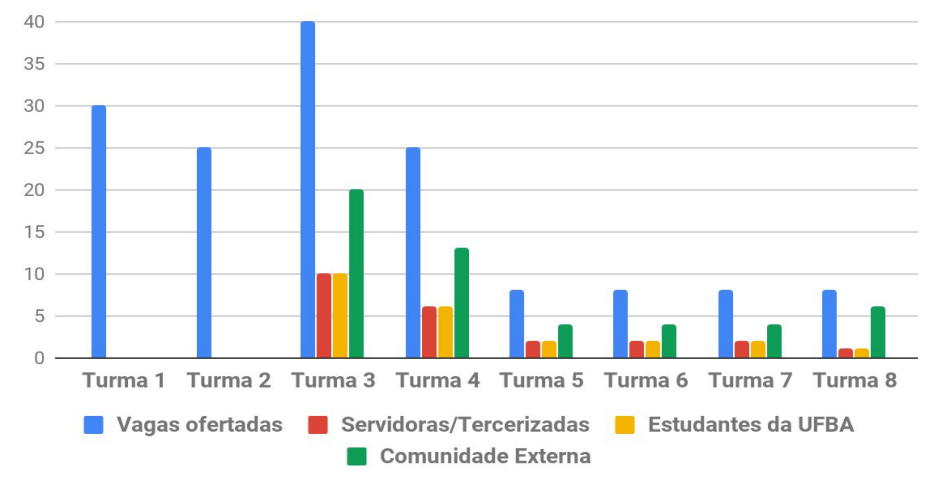

Figura 2. Evolução da política das cotas nas turmas.

Apesar do esforço, na Turma 7, por exemplo, todas as egressas eram estudantes da UFBA. Almejando um aumento mais significativo na participação da comunidade externa, o edital de seleção que regulamenta a Turma 8 altera a porcentagem de vagas reservadas desta, representando agora 75\% do total (Figura 2). A Turma 8 conta com 11 matriculadas, sendo 5 da comunidade externa e 6 estudantes da UFBA. Assim, ainda 
que o número de estudantes da UFBA sobreponha o das outras categorias, é possível notar uma evolução na participação da comunidade externa na ação de extensão.

\section{Considerações Finais e Trabalhos Futuros}

O cenário atual no que diz respeito ao gênero no CIProg têm se mostrado animador. A última turma de CIProg Nível 2 em 2018, por exemplo, teve 77,7\% de mulheres entre os matriculados e 83,3\% entre os concluintes. Esses dados, somados à entrada de egressas do CIProg, turmas exclusivas ou não, no MD-BA, e sua posterior atuação como instrutoras/monitoras das turmas exclusivas do CIProg demonstram que a ação consegue inspirá-las a continuar os estudos em programação e a promover inclusão de outras mulheres na área. Destaca-se também o esforço para a democratização do acesso ao curso (vide Subseção 4.1.) com a alteração na política de cotas para o edital que regulamenta a Turma 8 (vide Subseção 4.2.).

Conclui-se que, em trabalhos futuros, se faz necessária as análise do perfil: das egressas; das não-selecionadas; das matriculadas; e das desistentes, inclusos diversos recortes; bem como um acompanhamento das egressas. Raça, idade e situação socioeconômica são parâmetros interessantes a serem observados. A partir dessas análises será possível desenvolver estratégias a fim de evitar a evasão, aumentar o número de concluintes e, por conseguinte, auxiliar o cenário baiano na busca da equiparação de gênero na área de TIC.

\section{Referências}

Ferreira, A. C., Santos, J., Silva, R., Oliveira, A. T., Zabot, D., Santos, D. A. e Matos, E. S. (2016) "Hello World: relato de experiência de um curso de iniciação à programação.", In: Anais dos Workshops do V Congresso Brasileiro de Informática na Educação (CSBC 2016), p. 1306-1315.

Lobo, M. M. O., Figueredo, K. S. e Maciel, C. (2018) "A Mobilização de Resistência das Mulheres Negras na Computação e Tecnologias", In: $12^{\circ}$ Women in Information Technology (WIT 2018).

Maciel, C. e Bim, S. A. (2016) "Programa Meninas Digitais - ações para divulgar a Computação para meninas do ensino médio", In: Anais [do] Computer on the Beach, p. 327-336.

Maia, M. M. (2016) "Limites de gênero e presença feminina nos cursos superiores brasileiros do campo da computação", In: Cad. Pagu [online], n.46, p. 223-244.

Santos J. M. O., Ferreira, A. C. C., Oliveira, A. T. R., Santos, D. A. e Matos, E. S. (2017) "Meninas Digitais - Regional Bahia: os primeiros bits". In: $11^{\circ}$ Women in Information Technology (WIT 2017), p. 1253-1256.

Santos J. M. O., Pereira, K. A. S. e Santos, D. A. (2018) “O uso da programação para atração de mulheres à computação: relatos de experiência." In: $12^{\circ}$ Women in Information Technology (WIT 2018).

Sociedade Brasileira de Computação. (2017) "Educação Superior em Computação Estatísticas 2017", http://www.sbc.org.br/documentos-da-sbc/summary/133-estatisticas/1200-pdf-png-e ducacao-superior-em-computacao-estatisticas-2017, Março 2019. 